\title{
IMMEDIATE AND REMOTE EFFECTS OF RESECTION ON THE HYPERTENSION IN COARCTATION OF THE AORTA
}

\author{
BY \\ HAROLD W. MARCH, HERBERT N. HULTGREN, AND FRANK GERBODE \\ From the Stanford University Hospitals, San Francisco, California, U.S.A.
}

Received June 4, 1959

Twenty-five years ago Sir Thomas Lewis summarized the state of knowledge regarding this important congenital lesion (34)* and thought that "new records of cases can have little value unless they reveal new features of interest and importance to the study of the condition." Yet hardly more than a decade later the first patients with coarctation of the aorta were to be successfully operated upon in Sweden (11) and the United States (23). A new era of progress in the treatment and understanding of the pathological physiology of this lesion began. By 1953 Gross had operated on 270 patients (24), and more recently it has been possible to collect data on 1601 patients surgically treated by 36 surgeons (52). It is apparent that operative intervention for coarctation of the aorta has become widely practised. Its broad acceptance appears to be justified not only by the demonstration that the classical pulse abnormalities can be largely reversed $(5 \mathrm{a}, \mathrm{b})$, but also by the reasonable safety of the procedure and by the subjective improvement of patients $(7,8,24)$.

The cure of the characteristic hypertension has been included among the benefits of surgical treatment in reports from a number of clinics $(6,10,20,24,27,35)$. Indeed a fall in blood pressure does usually follow successful intervention, but most communications have described the condition shortly after the operative procedure, and the criteria for evaluation of the blood pressure response are usually referred to an arbitrary or ideal value. With few exceptions $(6,9,59)$ systematic observations at remote intervals after treatment have not been made, and in one of these (9) the conclusions appear to be at variance with the more numerous and optimistic results reported just after operation. In this latter work alone were the data given careful statistical treatment.

Obviously this question is of prognostic importance since the complications of hypertension are the cause of a quarter of the deaths in coarctation (24), and since in untreated cases there is a progressive increase in systolic pressure during the first two decades of life (6). Moreover, the issue is of interest from the theoretical point of view since the mechanism of most forms of hypertension is poorly understood, and that of coarctation has evoked considerable disagreement. The classical view that it is caused by the mechanical obstruction $(3,4,34)$ has been challenged on a number of grounds by those who hold that it is caused by an interference with the renal arterial flow producing a generalized increase in peripheral resistance $(38,44,45)$. Finally, there has been speculation about the mechanism and significance of the abdominal pain and the paradoxical rise of blood pressure that not infrequently follow resection of the coarctation $(2,43,47)$. These considerations suggested that an immediate and long-term study of the effect of operation on coarctation hypertension would be desirable.

\section{MATERIALS AND MethodS}

In the ten years, 1948-1958, 80 patients underwent surgery for coarctation of the aorta at Stanford University Hospital. In nearly all, the procedure was resection of the stenotic area followed by end-to-end

* For various reasons, an exception has been made for this paper in the usual method of quoting the references. 
anastomosis of the aorta. Only rarely was it necessary to divide the left subclavian and perform a subclavian-aortic anastomosis. In 8 instances an associated patent ductus arteriosus was ligated. There were 8 deaths occurring within six weeks of operation: one an infant of two months, one a child of two years, and the remainder adults.

In 58 of those with a successful operation sufficient information was available to include them in a study of the immediate blood pressure response to operation. This required that directly after it and for the following 10 to 14 days daily blood pressure determinations were available. These were tabulated separately and the median values for each day were plotted. There was good agreement between the pressures taken by physicians and by nurses, the mean difference for 20 randomly selected medians being 10.8 systolic and $8.8 \mathrm{~mm}$. $\mathrm{Hg}$ diastolic. The median reflects the middle value, and as such gives a central figure and, where the range is large, it minimizes the expression of large deviations. Although popliteal pressures were not available as a routine, observations regarding the character of the pulses in the leg were usually recorded. As a control group, patients undergoing ligation of a patent ductus arteriosus were compared since they would represent a sampling of patients without hypertension undergoing a surgical procedure involving a congenital anomaly in the same location.

Follow-up information is available on 39 of the original group of 58 patients. One died two years after operation of severe coronary artery disease complicated by ventricular septal defect: his blood pressure had been normal from the time of operation till his death. The remaining 38 patients were re-examined at intervals ranging from 1 to 9 years after surgery. Their general status was ascertained, special attention being given to the effect of the repair on pre-existing symptoms. Physical examination was always as complete as possible, and an attempt was made to record cuff pressures from all four limbs as a routine. The right arm pressure was recorded at intervals during and at the end of the examination, in order better to approximate the basal value. For the diastolic pressure both the points of muffling and of extinction were recorded, the latter point being taken as the diastolic level when the interval between the two points was significant. In 19 instances standard exercise was also done and the blood pressure responses recorded. Twelve-lead electrocardiograms and cardiac X-rays including posterior-anterior, lateral, and two oblique views were routinely made.

In the long-term study the tables and graphs will refer to the 27 consecutive patients who first responded to the follow-up summons. The 11 patients who were seen subsequently have been evaluated in exactly the same manner and their long-term results are not significantly different from the others.

In all phases of the study, patients were classified as having a normal or a raised blood pressure by reference to studies of the "normal" population. The compiled data of Nadas (37) were used for infants and children, and from the age of 16 the standards of Master (36). Patients with blood pressures two standard deviations or more from the mean at their age were considered to be hypertensive.

\section{The Period from Operation to Discharge}

From the composition of the patients and of the control group in this phase of the study (Table I), it will be seen that the mean ages are comparable but that the range for those with coarctation was wide. There was the usual male predominance.

TABLE I

Composition of Patient Study

\begin{tabular}{c|c|c|c|c}
\hline & $\begin{array}{c}\text { Number of } \\
\text { patients }\end{array}$ & Mean age, years & Sex & Procedure \\
\cline { 2 - 5 } $\begin{array}{c}\text { Immediate postoperative } \\
\text { study }\end{array}$ & 58 & $\begin{array}{c}19 \cdot 5 \\
\text { (Range: 0.25-55) }\end{array}$ & $\begin{array}{c}\text { M-41 } \\
\text { F-17 }\end{array}$ & $\begin{array}{c}\text { Resection of coarctation } \\
\text { and aortic anastomosis }\end{array}$ \\
\hline Control study .. & 25 & $\begin{array}{c}16 \cdot 4 \\
\text { (Range: 2-35) }\end{array}$ & $\begin{array}{c}\text { M-9 } \\
\text { F-16 }\end{array}$ & $\begin{array}{c}\text { Ligation and division of } \\
\text { ductus }\end{array}$ \\
\hline
\end{tabular}

Fig. 1 indicates that systolic hypertension was almost always present and generally diastolic hypertension also $(74 \%)$, confirming observations from other sources $(5,32,50,58)$. Fig. 2 indicates a clear tendency for the systolic, but not for the diastolic, pressure to rise with age.

Table II compares the blood pressure responses of the patients and controls before operation and for the first ten days after, and shows that on discharge the average pressure had fallen $25 / 10 \mathrm{~mm}$. 


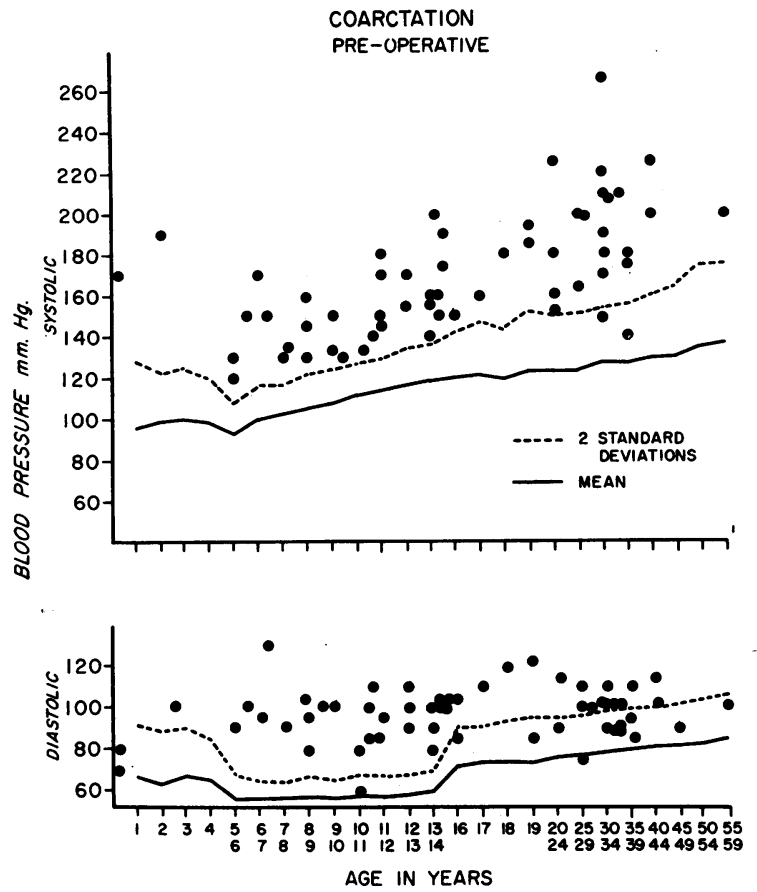

FIG. 1.-Systolic and diastolic pressures before operation recorded by the indirect cuff method are plotted against age. The mean and +2 S.D. lines represent values from normal population studies as described in the text: the -2 S.D. line has been omitted for simplicity. The high "normal" diastolic levels from ages 1-4 compared with the curve for the following decade is due to inconsistencies in recording technique, the point of muffling having been taken as diastolic pressure between the ages of 1-4 years. Systolic hypertension was almost invariable and diastolic hypertension usual.

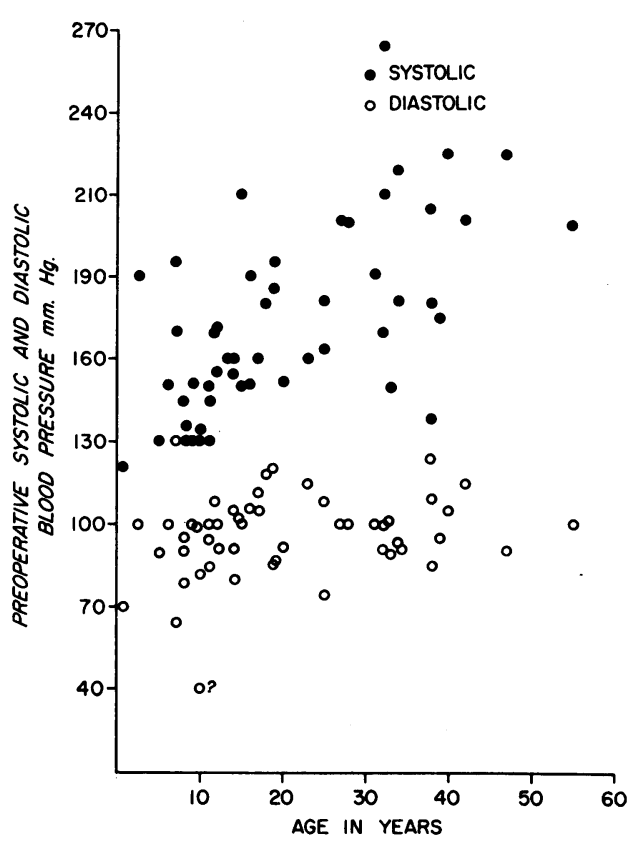

FIG. 2.-Systolic and diastolic pressures before operation are plotted against age. Although the diastolic pressure appears to be independent of age, the systolic pressure tends to rise with age.

TABLE II

Average Blood Pressure

\begin{tabular}{lr|c|c}
\hline & Coarctation & PDA \\
\hline Pre-operative.. &. & $168 / 96$ & $117 / 57$ \\
Post-operative day- & $148 / 88$ & $118 / 77$ \\
& 5 & $143 / 92$ & $119 / 77$ \\
& 5 & $149 / 107$ & $117 / 80$ \\
On discharge $\ldots$ & 10 & $153 / 90$ & $113 / 74$ \\
&.. & $143 / 86$ & - \\
\hline
\end{tabular}

in those with coarctation. But their average pressures are at all times higher than those in the patent ductus group, which experienced no significant alterations in average systolic pressure or in diastolic pressure after the first day. The immediate rise (to normal) of the diastolic pressure in the latter group was the anticipated consequence of closing an A-V fistula.

Although prompt blood pressure reductions did occur in some instances, slow reductions accompanied by intermittent rises were seen in 53 per cent of the group. Fig. 3 is an example of this pattern. Not infrequently abdominal pain or distension also occurred. Abdominal pain 
occurred in 16 per cent of the controls but in 31 per cent of those with coarctation where it tended to be more severe. "Immediate" rises of blood pressure (those occurring within the first 36 hours) were seen in 14 per cent of those with coarctation and in 16 per cent of the controls. "Delayed" rises (those after the first two days) were seen in 53 per cent of those with coarctation but in only 24 per cent of the controls. Fig. 4 shows both types, with the delayed rise quite sustained. This paradoxical behaviour of the blood pressure after operations for coarctation has been reported $(43,47)$, and immediate and delayed rises as used here correspond to the designations of Sealy (47).

The individual response of blood pressure to surgical treatment was variable. As expected, those with the highest basal levels had the greatest reductions. The fall in systolic levels was dependent

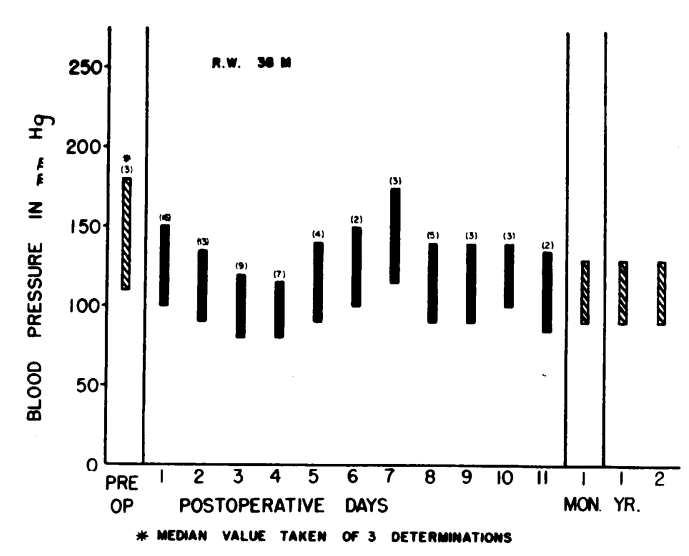

FIG. 3.-The course of the blood pressure in an individual patient. The hatched bars represent pressures taken by medical personnel and the solid bars those taken by nurses. The small numbers above the bars indicate the number of determinations done, and the bar represents the median value in each instance. Note the delayed type rise in pressure on the fifth day, following an initial fall to normal. At five year follow-up the blood pressure was $140 / 95$.

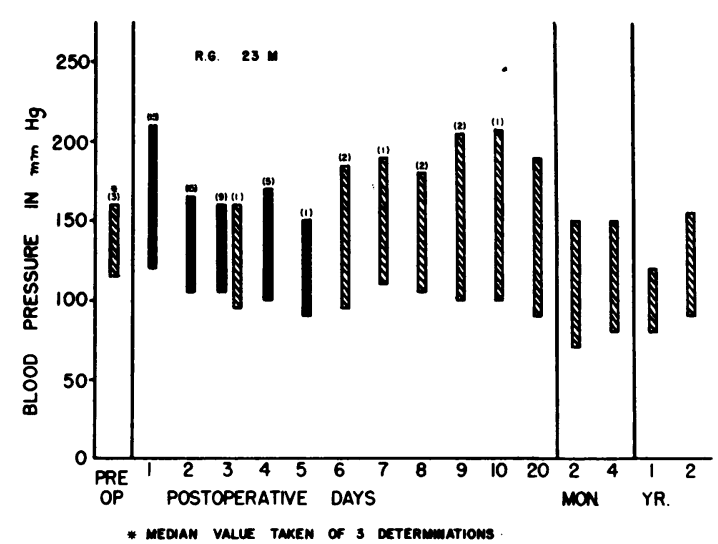

FIG. 4.-The conventions are identical with those of Fig. 3. Note not only an immediate rise in blood pressure on the first postoperative day, but also a secondary rise on the sixth day which had not declined at the time of discharge on the twentieth day. At five year follow-up this patient's blood pressure was $150 / 84 \mathrm{~mm}$.

on the systolic level before operation but was seemingly independent of the diastolic pressure (Fig. 5 and 6). Fig. 7 illustrates the analogous dependency of the diastolic pressure response on the preoperative diastolic level. In Fig. 8 there is an apparent tendency of the older patients to have larger systolic, though not diastolic, reductions than the younger ones, but this is a corollary of Fig. 2 which shows that preoperative systolic, though not diastolic, levels rise with age.

At the time of discharge from the hospital the mean fall in blood pressure for the entire group was $25 / 10$. This is quite comparable with the differences noted at a similar postoperative interval in studies elsewhere $(8,59)$. Fig. 9 further indicates the situation at the time of discharge. Only 33 per cent of the group could be considered to have a normal blood pressure, and where it was high, both systolic and diastolic pressures were raised in 29 per cent, the diastolic only in 14 per cent, and the systolic only in 24 per cent. Those who acquired a normal pressure did so gradually as expected (24) and on the average it was normal for the first time on the twelfth day, with a wide range from 1 to 22 days.

\section{The Late Results of Operation}

In Table III the most relevant data pertaining to the composition of the follow-up group are summarized. In a parallel column this is compared with the entire original group at the time of 


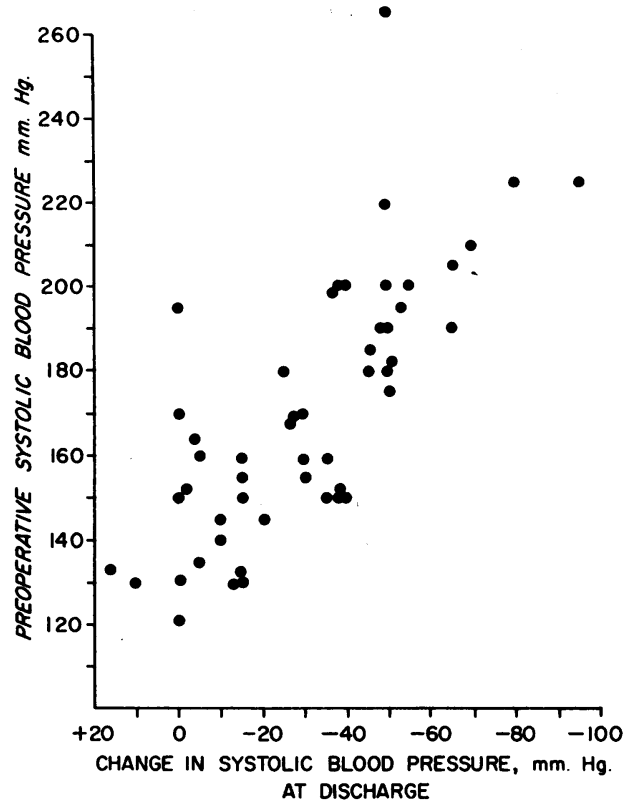

Fig. 5.-Scattergram, showing that the postoperative fall in systolic blood pressure was proportional to the systolic pressure before operation.

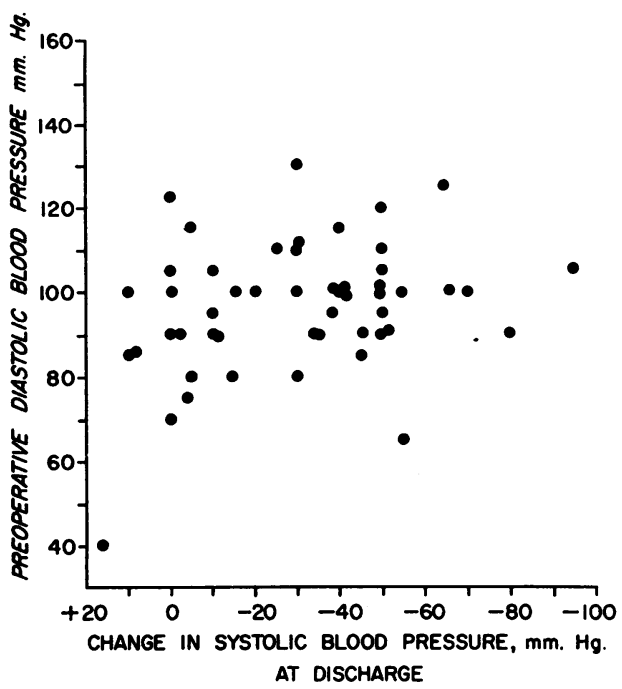

Fig. 6.-Scattergram, showing that the fall in systolic blood pressure after operation is independent of the diastolic pressure before operation.

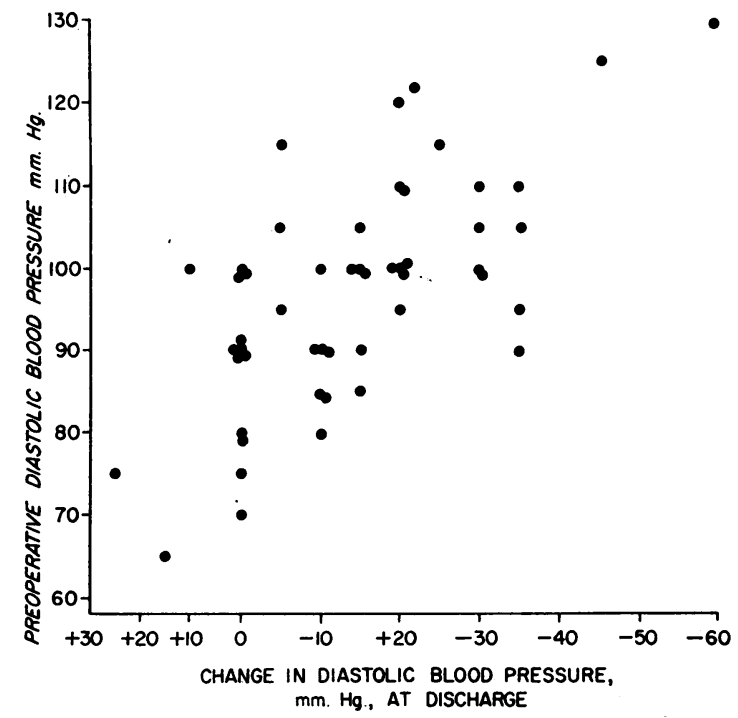

FIG. 7.-As with systolic pressures, the subjects with the highest diastolic levels before operation experienced the greatest change after operation.
- sYstolic

- DIASTOLIC

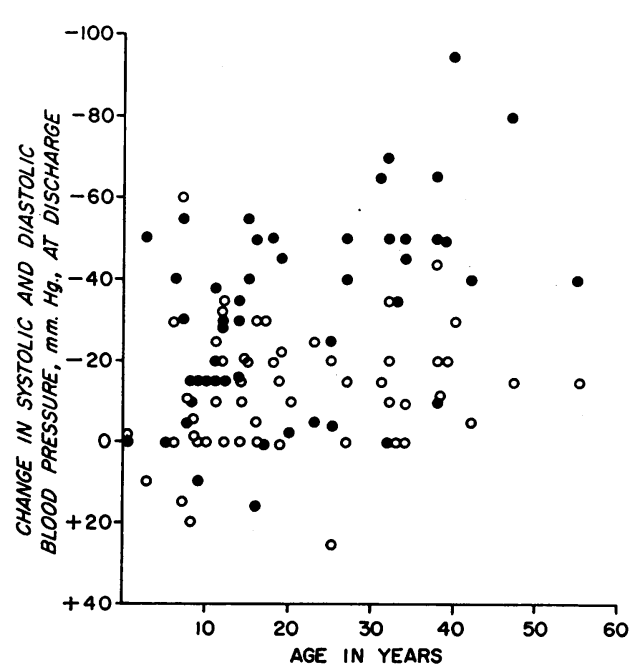

FIG. 8.-This scattergram is a corollary of Fig. 2, 5 , and 7. As in the case of the original blood pressure levels, the post-operative fall for systolic pressure, but not for diastolic pressure, was greater with age. 
hospital discharge. It will be seen that they are representative of the original group, and constitute an acceptable random sample. For example, the blood pressures before and immediately after operation were similar in the two groups and at discharge the numbers with normal and with raised blood pressure were similar.

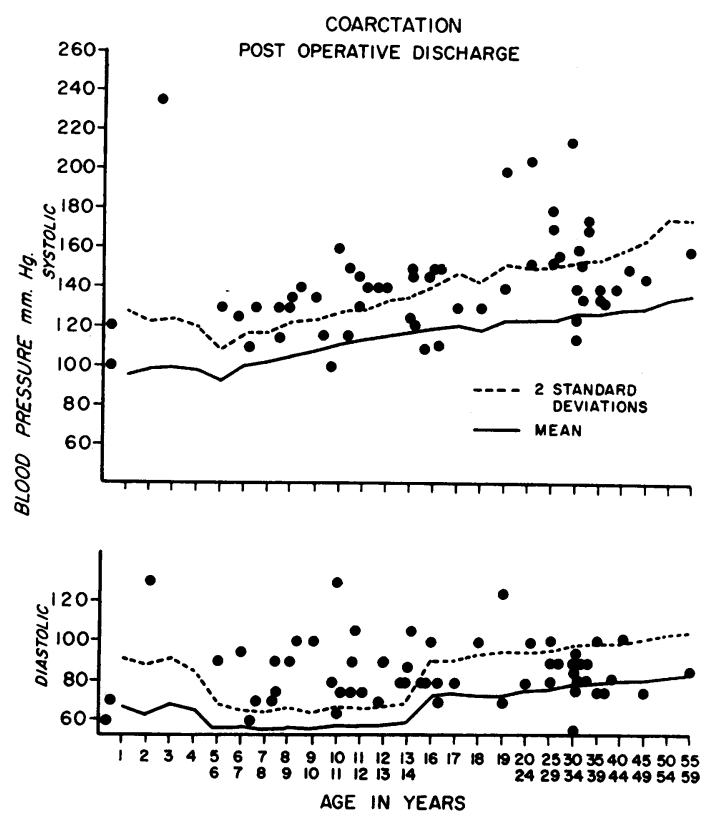

Fig. 9.-This illustration has the same conventions as Fig. 1. It shows that at discharge a substantial majority of subjects were still hypertensive.

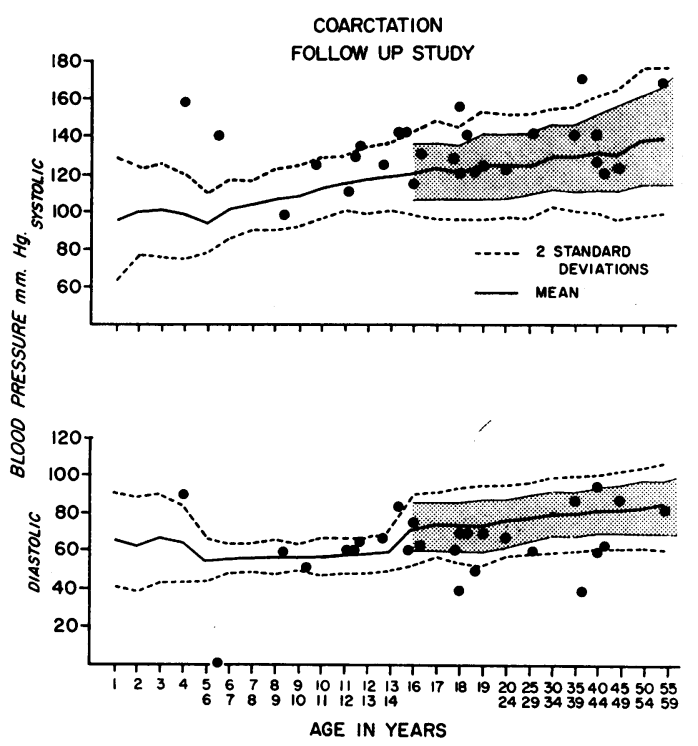

FIG. 10. - The \pm 2 S.D. lines are drawn in, and the stippled area represents the central 80 per cent of the "normal" population. At long-term follow-up most of the abnormally high systolic and abnormally low diastolic pressures belonged to subjects with significant aortic regurgitation or a difference of $20 \mathrm{~mm}$. or more between the cuff pressure in the arms and legs.

TABLE III

LONG-TERM STUDY

\begin{tabular}{|c|c|c|c|c|}
\hline & 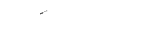 & & Follow-up group & Original group \\
\hline $\begin{array}{l}\text { Number of patients } \\
\text { Mean age of patients } \quad . \\
\text { Duration of follow-up (mean and rang } \\
\text { Mean blood pressure before operation } \\
\text { Mean blood pressure at discharge } \\
\text { Fall in blood pressure on discharge } \\
\text { Normal blood pressure on discharge } \\
\text { Systolic and diastolic hypertension on }\end{array}$ & $\begin{array}{ll}\cdots & \cdots \\
\ddot{g e} & \cdots \\
\cdots & \cdots \\
\cdots & \cdots \\
\ddot{\text { discharge }} & \quad \cdots\end{array}$ & $\begin{array}{l}\cdots \\
\cdots \\
\cdots \\
\cdots \\
\cdots \\
\cdots\end{array}$ & $\begin{array}{c}27 \\
18 \\
3.9(1-9) \mathrm{yr} \\
171 / 98 \\
139 / 82 \\
32 / 16 \\
37 \% \\
29 \%\end{array}$ & $\begin{array}{c}58 \\
19 \cdot 5 \\
168 / 96 \\
143 / 86 \\
25 / 10 \\
33 \% \\
29 \%\end{array}$ \\
\hline
\end{tabular}

None of these patients had experienced any of the sequelæ of hypertension associated with coarctation of the aorta, nor had there been any instances of endocarditis or aortic dissection. Subjectively they felt well and led active lives although there were occasional complaints of palpitation or "nervousness" and rarely dyspnœa. Those who before operation had experienced fullness in the head or neck, dizziness, or paræsthesiae in the lower extremities were relieved of these symptoms. 
In contrast, physical findings were still plentiful. The left radial pulse was palpably weaker than the right in half of the cases, the average difference in brachial systolic pressures being $20 \mathrm{~mm}$. (range 6 to $33 \mathrm{~mm}$.). In 5 cases the femoral pulse was weaker than the right radial pulse and/or the popliteal systolic pressure was less than the right brachial pressure by $20 \mathrm{~mm}$. or more. Once the femoral pulse could not be palpated nor could the popliteal pressure be recorded. In all other instances the popliteal systolic pressure equalled or exceeded the brachial pressure.

Apical heaves [3], carotid [3], and suprasternal [10] pulsations were not uncommon, and these findings together with the palpably wide pulse pressure at times suggested a hyperdynamic circulation. Systolic murmurs were widely distributed over the præcordium, neck, axillæ, and back (see Fig. 11). Basal and left sternal border diastolic murmurs also, presumably of aortic regurgitation,

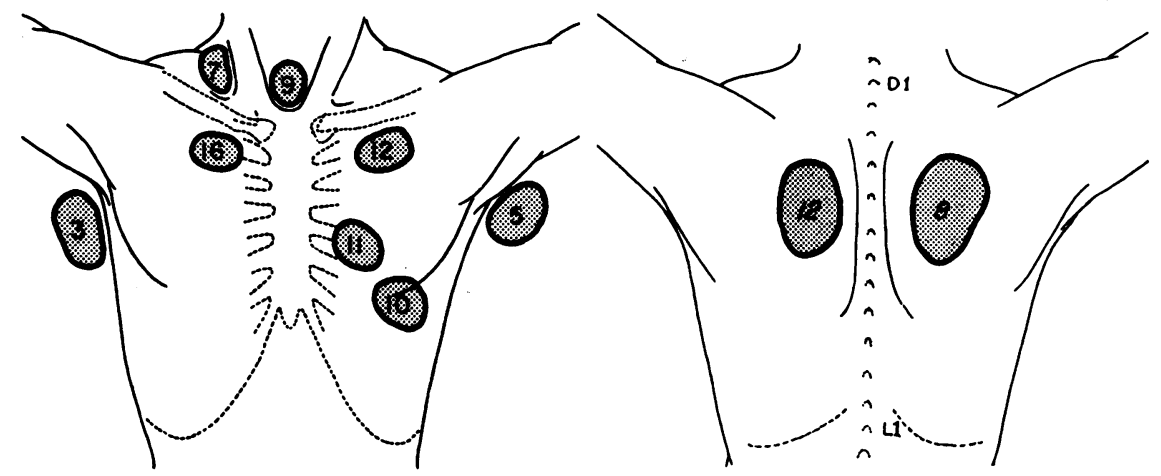

FIG. 11.-The distribution of systolic murmurs over the præcordium, neck, axillæ, and interscapular regions in 24 patients. In addition, diastolic murmurs were heard at the base and/or left sternal border in five cases, and an apical diastolic murmur in a single case.

were heard in 5 patients, in 4 of them with the peripheral signs of aortic regurgitation. In only one of these was the diastolic murmur not heard before operation, and here the regurgitation was thought to be trivial. An apical diastolic rumble suggesting mitral stenosis was heard in one patient.

Twenty-four electrocardiograms at long-term follow-up were compared. In 13 that had been normal no significant change occurred, in 1 with abnormal $\mathrm{T}$ waves before operation the trace became normal, in 4 abnormal $\mathrm{T}$ waves appeared postoperatively for the first time in the absence of hypertension or an aortic valve lesion. Left ventricular hypertrophy was present in two subjects with aortic regurgitation, and right ventricular hypertrophy in one child before and after. In one instance prolonged A-V conduction time existed before and after, and once incomplete right bundle-branch block appeared for the first time after operation.

Since discharge from hospital, the group had experienced an additional mean fall in blood pressure of 10/19. Table IV and Fig. 10 indicate that 74 per cent of the group were now within two standard deviations of the mean blood pressure for their respective ages. Seven patients still

TABLE IV

LONG-TERM STUDY

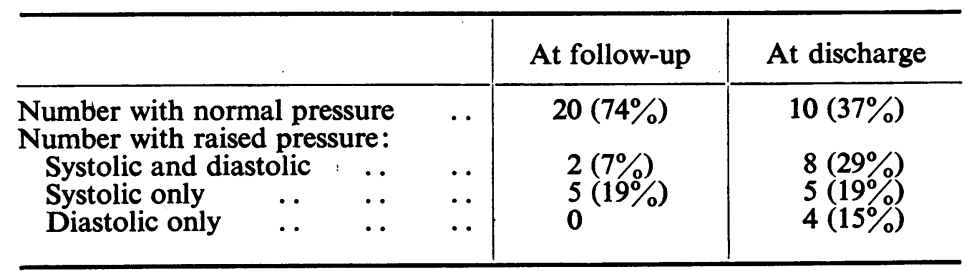


had systolic hypertension, and two of these diastolic hypertension also. Those who had a normal blood pressure for the first time had experienced additional reductions of $19 / 18$, which on the systolic side represented a greater reduction than that of the group taken as a whole.

Further analysis of those remaining hypertensive discloses some points of interest. The two with systolic and diastolic hypertension had popliteal blood pressures that were lower than the right brachial by $20 \mathrm{~mm}$. or more, and residual coarctation could not be excluded. In one of these, however, the personal physician recorded blood pressure levels that would be considered normal by the criteria employed in this study. Of the 5 with systolic hypertension only, 2 had dynamically significant aortic regurgitation, and in one of these the femoral pulse was not palpable nor the popliteal blood pressure recordable. One had a $24 \mathrm{~mm}$. difference in the popliteal systolic pressure as well as an aortic diastolic murmur and one had a diastolic murmur, wide pulse pressure, and rapid brachial upstroke that probably but not certainly indicated significant aortic regurgitation. The remaining patient had a wide pulse pressure without a diastolic murmur and without a discrepancy in the popliteal pressures. But here, too, the personal physician was able to record normal blood pressures in the familiar consulting room environment.

Fig. 10 also indicates that even if the line embracing $+1 \cdot 28$ S.D. (which would include $80 \%$ of the "normal" population (36)) rather than the two S.D. line were to be considered the limit of normal blood pressure, as Master has suggested, our final results would not be appreciably altered. The data for all 38 patients strongly suggest that when those with significant aortic regurgitation and those with questionable residual coarctation are excluded, the incidence of persisting hypertension after operation for coarctation does not exceed 5 per cent.

\section{DisCUSSION}

In evaluating the effectiveness of the relief of the hypertension certain pitfalls must be accepted. Assessments made soon after operation may be misleading since time may be important in a long-standing condition like hypertension. Moreover, the attempt to divide them into normal and those with persisting hypertension may cause difficulties owing to the very definition of terms. Pickering with impressive supporting evidence (41) maintains that there is no clear division: rather a continuous variation with advancing age, in which the frequency distribution for blood pressure shifts towards the higher values. A precise level for hypertension therefore cannot be determined. Furthermore, the mortality from cardiovascular disease rises steadily with increasing systolic and diastolic pressure, and there is a significant increase even with moderate rises. The curve rises first slowly, then rapidly in a non-linear manner, but without a sharp break. The ideal way of studying the curability of coarctation hypertension would be to follow the series through life in an attempt to determine whether there is an increase over the expected cardiovascular deaths. In clinical research this approach is difficult.

In spite of these difficulties there seems no alternative but to accept the statistical approach with its useable tools, the distribution curve and the standard deviation. In terms of standard deviation from a measured mean, where the distribution is normal (Gaussian), the prediction is that two-thirds of the individual values will be within \pm 1 S.D. of the mean, and about 95 per cent within \pm 2 S.D. of the mean. The statistician regards departures from the mean of more than \pm 2 S.D. as "significant", i.e. the probability that the variation from the normal distribution is due to chance alone is in the order of 5 per cent ( $2 \frac{1}{2}$ above $+2 \frac{1}{2}$ below). Where the distribution is skewed the percentage exceeding \pm 2 S.D. may be increased.

If the normal population is tested in a random manner so that adequate sampling is made of blood pressures at suitable age intervals throughout life, the data can be treated in the manner described above, and a curve of mean blood pressure against age plotted together with lines representing \pm 2 S.D. of that mean. It would probably be safe to say that the values lying within \pm 1 S.D. of the mean are normal, and that values lying outside \pm 2 S.D. are abnormal. It has been suggested that the clearly normal range be extended to \pm 1.28 S.D. so that it would embrace 80 per cent of the values above and below the mean (36). Pickering is inclined to accept this "so long as it is clear that in this connection normal pressure represents the central 80 per cent and the pathological pressures the extreme 5 per cent of values found at that age in a population sample" (41).

In this study the interpretation cited above has been accepted, and Fig. 1, 9, and 10 are scattergrams for systolic and diastolic pressures of the patients, before operation, on discharge, and at the follow-up, plotted 
by age against the mean and standard deviation lines. In Fig. 1 and 9 the mean and +2 S.D. lines alone are drawn, the -2 S.D. line having been omitted for simplicity. In Fig. $10 \pm 2$ S.D. lines have been drawn as well as a hatched area (above the age of 16) embracing the central 80 per cent.

Since the patient material ranged from infancy to age 54 it was necessary to have "normal" data to cover the entire range. Unfortunately no single source could furnish it all. From newborn to the age of 16 the study of Nadas was used, and the apparently higher values for diastolic blood pressure below the age of 4 years is due to the fact that there the point of muffling rather than extinction was taken as diastolic pressure. Above the age of 16 the compiled material of Master was chosen: this was gathered from 16 industrial plants in the United States and represents blood pressures taken among men and women applying for work. Such statistical studies may be prone to factors favouring unconscious selection and/or non-random sampling. Obviously in this study people who would not or could not apply for work were not sampled. Information about the manner of recording blood pressure is not detailed and, for example, it is not stated how the diastolic pressures were recorded in all plants, but it is doubtful whether any study could eliminate all possible sources of error. The similarity of the data collected by Master to those recorded in England with a very different type of protocol tends to strengthen the validity of the norms that have been selected (28). Since writing this paper the splendid population study at Bergen in Norway has come to our attention. (4b). The mean and standard deviation of systolic blood pressure in 27,718 men between the ages of 20 and 60 years correspond closely with the values of Master. Although sex differences in blood pressure are demonstrable in Master's figures the mean difference did not exceed $8 \mathrm{~mm}$. systolic or $4 \mathrm{~mm}$. diastolic at any age, so the male values were used in this study where roughly two-thirds of the patients were men.

Before operation the group almost uniformly had systolic hypertension, there being only two exceptions to this. The two exceptions were a 38-year-old man with a systolic pressure of 140 and a 33-year-old woman with one of $150 \mathrm{~mm}$. In reviewing 175 reported cases King (32) found 19 with levels below $140 \mathrm{~mm}$. Ninety per cent of 225 patients reported by Steele had systolic blood pressures in at least one arm exceeding $140 \mathrm{~mm}$. (5). A possible source of error is introduced when the left arm only is recorded. In King's series the mean systolic difference in the arms was only $5 \mathrm{~mm}$. but there were 10 cases in which the disparity was large, the pressure on the left being within normal limits: he postulated that the left subclavian artery was involved in the stenosing process in these instances. Neither of the two patients here considered normal was in circulatory distress: in one the pressure was known to be a right-arm value, in the other the side was not noted.

The mean pre-operative arm-cuff blood pressure of the group was 168/96, and 74 per cent had raised diastolic blood pressures in the arms. Steele (50) found 44 per cent with a raised diastolic pressure in at least one arm: he used a level of $100 \mathrm{~mm}$. as the upper limit of normal, but the method of recording the diastolic pressure was not described. Fig. 1 indicates that, if Steele's level were to be used for our material, our percentage would be more similar (around 50\%) since a number of children and adolescents were hypertensive by our criteria although their diastolic pressures were lower than $100 \mathrm{~mm}$. In only two was the diastolic pressure above 120 and in only 11 was it $110 \mathrm{~mm}$. or greater. In spite of our figure of 74 per cent with diastolic elevations these were of modest degree, consistent with the mean value of $96 \mathrm{~mm}$. These mean levels, both systolic and diastolic, are in good agreement with studies elsewhere. In Brown's series of 21 patients (5a) the mean intraradial blood pressure was 196/96, Campbell (6) reported 190/105 for his group at the age of 17 years, and Counihan a mean pressure of 178/99.

After operation it was not the rule for the blood pressure to fall abruptly and to remain fixed at normal levels, although this was seen sometimes, especially where the pressure had not been very high. Gross (24) says that the pressure falls mainly over a period of two or three weeks, and he ascribed this to the gradual dilation of the vascular bed below the coarctation, but not much beyond that period. Clagett (7), on the other hand, says that the reduction may not be maximal for months. The magnitude of the fall has not varied strikingly among different investigators. Cleland reports a mean decline of $32 / 16 \mathrm{~mm}$. in the initial period in 40 cases (8), and in Glenn and O'Sullivan's patients it amounted to $35 \mathrm{~mm}$. systolic. Wright's estimate for 10 patients two weeks after operation was $23 / 8$, and this is very similar to the difference of $25 / 10 \mathrm{~mm}$. of the present study, at the time of their discharge.

The classification of immediate post-operative results has been very variable. Crafoord (10) after his first 22 operations reported return to "low normal values". Gross (24) has claimed that 88 per cent of his 270 patients have experienced reductions to below $140 \mathrm{~mm}$. systolic for adults and for children to levels commensurate with their age. On the other hand, Glenn and O'Sullivan (20) found that 50 per cent of 18 patients had systolic pressures above $140 \mathrm{~mm}$., and Hallenbeck (27) found that only 50 per cent of 31 patients had levels of $130 / 90 \mathrm{~mm}$. or lower.

2C 
However, in spite of reductions of blood pressure among patients in this series, which were roughly similar to those cited, they were large enough to result in normal levels by our criteria in only 33 per cent, two-thirds of the remainder having both systolic and diastolic hypertension. Admittedly, some of the diastolic rises were of small magnitude and fall into the pressure trough between the ages of 5 to 14 years (Fig. 9), which may be due to low levels for the disappearance of the sounds in this age group. In the children between 1 to 4 years of age where the point of muffling was used instead, the diastolic pressures are normally higher. Nevertheless, even if this trough is eliminated by drawing a straight line for +2 S.D., there would still be one-third with diastolic blood pressures greater than $84 \mathrm{~mm}$. in the 1 to 15 year age range, or greater than $92 \mathrm{~mm}$. in the older patients.

It is tempting to relate this mediocre "cure" rate at discharge to the phenomenon of immediate and delayed blood pressure rises in the post-operative period often accompanied by abdominal pain. Fig. 3 and 4 show examples of this. Eight $(14 \%)$ of the patients had immediate rises and $31(53 \%)$ delayed rises, and in both types the systolic as well as the diastolic measurements were often involved. The immediate rises represented an increase over the pre-operative pressure, the mean change being $+20 / 13 \mathrm{~mm}$. In one instance of immediate rise, a coexisting patent ductus was tied in a 10-year-old girl: the diastolic pressure of $80 \mathrm{~mm}$. rose after operation to $100 \mathrm{~mm}$. and remained there until the seventh day whereupon it returned to its original level.

The delayed rises began as early as the 2 nd and as late as the 7 th day with the distribution being most frequently at the 3rd and 5th days. A rise is here defined as a departure of $20 \mathrm{~mm}$. or more systolic pressure and/or $10 \mathrm{~mm}$. or more diastolic pressure over the lowest value attained at any time after the second day in hospital. The mean delayed rise for the entire group was $30 / 20 \mathrm{~mm}$., but there was a range up to 75 systolic and $40 \mathrm{~mm}$. diastolic. The duration of these rises was as brief as one day on the one hand, and on the other so long that it had not returned at the time of discharge. A return is defined as a pressure within $10 \mathrm{~mm}$. systolic of the level before the rise. In 12 patients the rise lasted 5 days or less, in 9 it spanned a 6- to 12- day interval, in 2 it lasted for 17 to 21 days, and in a third, death occurred on the 20th day of aortic necrosis and hæmorrhage. The blood pressures of 8 patients still had not returned at the time of discharge. In one there was still no change at 6 weeks when the patient was lost to follow-up. An additional patient died at six weeks of a ruptured aneurysm at the operative site. The remainder were followed and became part of the long-term study. One, with severe aortic regurgitation still has a raised systolic pressure. One with weak femoral pulses suggesting further study for residual coarctation has had a decline in the interim but he was still hypertensive, and the remaining four have normal pressures.

Abdominal pain was also a part of this complication of the postoperative period, having occurred in 31 per cent of the group. It was often accompanied by distension. It was not so frequent as the blood pressure elevations and no good relationship between the two could be established. It did not distinctly parallel either the height or duration of the blood pressure elevations, and often one could not distinguish its significance from that of routine postoperative discomforts. However, abdominal pain was prominent in the two hypertensive patients who died within six weeks of aortic necrosis, aneurysms, and hæmorrhage.

A comparison of the incidence of the above syndrome in the group as a whole with the 19 patients with normal blood pressure at discharge does not establish any striking differences. Nine of the latter $(47 \%)$ had delayed rises, accompanied by abdominal pain in four instances. The time of onset was the same as for the entire group, but in only one instance did the rise last more than six days, and obviously in all cases the remission would have occurred prior to discharge. It is apparent that in this group the episodes were less protracted.

These experiences indicate that paradoxical postoperative hypertension is a frequent phenomenon, occurring almost as often among those who have a normal pressure at discharge as among those who have not. As such it is a cause of the well-established pattern of slow or delayed falls in blood pressure postoperatively, and since the rises are not infrequently protracted beyond the hospital interval, it is also a reason for the poor immediate "cure" rate. The experience does not, however, confirm that it is directly instrumental in the eventual prognosis or that it is a cause of lasting hypertension. It may be indirectly responsible for postoperative deaths from hæmorrhage since two of the patients in the group died from perforations of the aorta within $2 \mathrm{~cm}$. of the anastomatic site.

Some pertinent observations are contained in the reports dealing with this problem. Benson and Sealy (2) in 1956 presented the protocols of two patients, and in an illuminating discussion they cited the similar experiences of Lober and Lillehei, and Perez-Alvarez and Oudkerk. Their two patients had abdominal pain, and on laparotomy gangrene of the small intestine was present in each instance. One eventually came to necropsy: profound changes had occurred in the arteries of the intercostal spaces, the diaphragm and most of the abdominal viscera, especially the gastrointestinal tract, liver, spleen, and kidney. The larger vessels were the site of medial necrosis, but the smaller ones were even more extensively involved, transmural œdema and eosinophilic fibrinoid necrosis being attended by an intense cellular reaction. In general the calibre of the major abdominal arteries tended to be small. Of great interest was the absence of similar changes in the vasculature above the site of coarctation. The selectivity of the arteritis for the 
regions below the coarctation, the predisposition of the bifurcation areas, and the possible underdevelopment of the larger splanchnic vessels suggest that changes in hæmodynamics after operation rather than circulating pressor substances or toxins are the cause. The distension of this underdeveloped bed by increased mean and pulse pressures may have been directly injurious. There is considerable support from studies in experimental arteritis that abrupt rises in blood pressure as well as the degree of rise in experimental hypertension can be responsible for necrotizing arterial lesions indistinguishable from periarteritis nodosa, and that vessels protected by a clamp are spared these changes. Individual variations in susceptibility to these lesions are apparent even in the laboratory, and the rabbits and rats usually chosen for these experiments are known to develop arterial lesions with relative ease.

In a later communication Sealy reviewed 30 operated coarctation cases (47), of whom seven had immediate rises and 14 had delayed rises, accompanied in 6 by abdominal pain. He concluded that the immediate type might well be due to a disturbance in the pressor receptors in aortic and carotid arteries which had been set at a high level, and clinically this event appeared to be of little significance. In the delayed type hypertension persisted from 6 to 14 days, the longest duration being in a patient who developed bowel necrosis. The author points out, perhaps without sufficient qualification in view of the paucity of direct supporting evidence, that the duration of the hypertension was dependent upon the severity of the vascular changes. He concludes that this delayed type of blood pressure rise is not followed by any residual hypertension or demonstrable vascular damage. However, a month after resection, a boy of 20 years had a pressure of $158 / 80 \mathrm{~mm}$., two children aged 5 and 6 of $150 / 90$ and $150 / 70 \mathrm{~mm}$. respectively, and a boy of 16 one of $140 / 90 \mathrm{~mm}$.

In another study the incidence of abdominal pain after operation for coarctation was studied in 73 patients (43): 14, divided into three groups according to the severity of symptoms were cited. Ten had mild abdominal pain more or less non-specific and consisting of one or more of the following: abdominal distension, abdominal tenderness, ileus, or vomiting. Four had similar but severer symptoms, and comprised the second group. The third group also consisted of four patients, but here the symptoms were so severe that laporotomy was performed. Two of these had previously been reported by Lober and Lillehei, and they had had necrotizing panarteritis with intestinal infarction. The third had a negative exploration but died, as did two of our patients cited above, of aortic rupture. The fourth had only mesenteric lymph node enlargement and eventually recovered.

The latter two examples are of special interest to the present authors. In the two cases of this series already alluded to, death occurred from 2 to 6 weeks after operation from aortic rupture and hæmorrhage. Careful review of autopsy slides failed to show any arteritis. In addition, three other patients who died from 3 to 5 days after operation showed no evidence of arteritis at necropsy. It is apparent that postoperative hypertension and abdominal pain can occur in the absence of necrotizing vascular lesions, and if the above considerations are correct these lesions are secondary to a factor that is responsible for the hypertension in this peculiar syndrome, and perhaps for the pattern of slow and protracted blood pressure responses following operations for coarctation generally.

Though there is a paucity of sound experimental data pertaining to the identity of such a mechanism, a few points may be mentioned. It is likely that reconstruction of the aortic lumen at operation increases the effective outlet chamber area and reduces the tension within the chamber. The work of Heymans (31) has indicated that tension and resistance to stretch of the arterial wall at the location of the carotid sinus pressor-receptors are fundamental factors in regulating and modifying systemic arterial pressure. In a review of the carotid sinus mechanism, Pickering (41) cites the studies of Koch et al. which demonstrate that when the carotid sinus and depressor nerves are sectioned in rabbits the animals develop hypertension. In the dog also hypertension follows the procedure and is accompanied by increased cardiac output and blood flow to the limbs. Ford (5) found that after denervation of the carotid sinus in a patient for relief of repeated syncope, the blood pressure rose from $120 / 80$ to $240 / 140 \mathrm{~mm}$, and death occurred from multiple cortical hæmorrhages. These experimental and clinical experiences suggest that blood pressure responses may be profoundly altered by the responses of the carotid sinus.

Another feature of carotid-sinus-induced hypertension is its prominent vasomotor and reflexogenic features. In the rabbits tachycardia was always present and blood pressure could be reduced by a variety of dermal and tactile stimuli. The arterial pressure appeared unusually susceptible to splanchnic section, injection of vasoactive substances, and hæmorrhage. In dogs cardiac output was increased and hypertension did not occur in totally sympathectomized animals.

Although the pre-operative cardiac output was increased in a case measured by the acetylene method (22), this parameter is usually normal in coarctation (3); Haf kenschiel, however, found increased cerebral blood flow and oxygen consumption in two patients (30). In patients studied from 4 to 7 years after operation the cardiac index was uniformly normal (59). Two patients, ages 11 and 16 years, with postoperative pressures of $170 / 97$ and $178 / 97 \mathrm{~mm}$. soon after operation were studied in this laboratory and their cardiac indices were rather high, $6 \cdot 3$ and $5.51 . / \mathrm{min} . / \mathrm{m}^{2}$ respectively, the peripheral resistances being normal.

Clinical experience also appears to indicate that the postoperative hypertension is attended by a strong sympathetic component. Tachycardia may be present and the patient may be alert and restless and may 
require sedation. Furthermore, these rises may be readily controlled by sympathetic blocking agents. It has become a practice in this hospital, and in others, to employ a ganglion-blocking agent routinely where there is any indication that postoperative blood pressure rises are occurring, and this practice has modified the duration and extent of the measurable rises in some of our patients.

The foregoing considerations lead us to accept as a working hypothesis the speculations of Sealy (47) that the immediate type of hypertension may be due to reflexes from aortic and carotid pressor receptors which had been set at a high level before operation, and after it, with tension in the aortic wall reduced, may cease to act as buffers. He quotes the work of Kezdi, demonstrating that after local blockade of carotid receptors in hypertensive subjects, there is a pressure rise commensurate with the pre-existing levels. This mechanism might also operate to produce more protracted hypertension and in susceptible subjects undergoing abrupt rises this may cause necrotizing arteritis in a splanchnic bed unaccustomed to such rises.

The results of our remote study indicate that substantial reduction in blood pressure may continue after discharge from hospital. Since the examinations were not conducted at regular intervals it cannot be stated when the nadir is reached. Although the difference between discharge and follow-up blood pressure for the entire group was only $10 / 19 \mathrm{~mm}$. $\mathrm{Hg}$, the difference for those whose pressure was not normal at discharge was $19 / 18 \mathrm{~mm}$. $\mathrm{Hg}$, which is considerable when it is recalled that the initial mean reduction for the 58 patients was only $25 / 10 \mathrm{~mm}$. $\mathrm{Hg}$. The striking difference in diastolic levels needs special comment. No doubt some of this difference is more apparent than real. In the follow-up study we have taken diastolic pressure at the point of extinction. Not only the patients with aortic regurgitation, but some without this lesion, had large intervals between muffling and extinction, so that low diastolic levels were recorded. Observers noting the point of muffling in earlier records would register a higher value. In any case, diastolic hypertension was present in only 2 of the total of 7 patients with persisting high blood pressure at the final follow-up. Moreover, these rises were modest indeed: a 4-year-old had a diastolic pressure of $90 \mathrm{~mm}$. and a 15 -year-old had $84 \mathrm{~mm}$. $\mathrm{Hg}$, just at the +2 S.D. line.

When possible coexisting lesions are ignored, the figure for persisting hypertension is 7 in 27 or 26 per cent. However, coarctation operations cannot be expected to cure the systolic hypertension of aortic regurgitation. Nor can it be assumed that patients with weaker femoral pulsation in whom the popliteal pressure was a minimum of $20 \mathrm{~mm}$. less than the brachial pressure have no significant residual coarctation. It has been estimated that the aortic lumen must be reduced from 45 to 55 per cent before the femoral pressure begins to change. In five patients the difference was greater than $20 \mathrm{~mm}$. $\mathrm{Hg}$, whereas all the others had equal or greater pressures in the lower limbs: 4 of the 5 were hypertensive and the two without aortic regurgitation are the two with diastolic as well as systolic hypertension. It would seem proper in estimating the incidence of persisting hypertension, i.e. blood pressure outside the +2 S.D. line, to exclude those in the above categories, and if so the incidence does not exceed 5 per cent. A look at Fig. 10 shows that, even if the central 80 per cent line, the upper limit line of Master, were to be considered, only two additional patients would fall outside that limit. One of these was a 57-year-old man operated at the age of 55 who had at least one cerebral vascular episode and probably complicating arteriosclerosis and essential hypertension. The second was a 20 -year-old boy who was otherwise well. It is apparent that the estimated "cure" rate would not be changed appreciably by cutting off at the line advocated by Master.

In conclusion, one may inquire whether this study has any bearing on the possible mechanism of the hypertension present in coarctation. We have no direct evidence, but the high cure rate at 1- to 9-year follow-up and the complete absence of recurring hypertension suggest that it is a direct consequence of the coarctation of the aorta itself and that it can be regularly reversed when this is corrected.

\section{Summary}

The blood pressure responses of 58 patients having an operation for coarctation of the aorta were studied from the immediate postoperative period to the time of discharge from the hospital. Thirty-nine of these were seen at long-term follow-up ranging from 1 to 9 years later.

The reduction in blood pressure after operation was slow and on discharge only 33 per cent had reached a normal level. The phenomenon of paradoxical rises in the immediate postoperative period is described as a contributory factor to the pattern of blood pressure response, and its significance and possible causation are discussed.

Further blood pressure reductions were noted after discharge from hospital and in the group followed over the long-term interval persisting hypertension was uncommon when those with aortic regurgitation or possible residual coarctation were excluded.

The mechanism of coarctation hypertension is discussed and it is suggested that the observed behaviour of the hypertension can be explained by the hæmodynamic factors caused by the coarctation itself, without invoking renal ischæmia and/or increases in peripheral vascular resistance. 


\section{REFERENCES}

1. Barker, H. C., and Clark, J. K. (1950). Bull. Amer. Coll. Surg., 35, 53.

2. Benson, W. R., and Sealy, W. C. (1956). Lab. Invest., 5, 359.

3. Bing, R. J., Handelsman, J. C., Campbell, J. A., Griswold, H. E., and Blalock, A. (1948). Ann. Surg., $128,803$.

4a. Blumgart, H. L., Lawrence, J. S., and Ernstene, A. C. (1931). Arch. intern. Med., 47, 806.

4b. Boe, J., Humerfelt, S., and Wedervang, F. (1957). Acta med. Scand., 99, Suppl. 321.

5a. Brown, G. E., Pollack, A. A., Glagett, O. T., and Wood, E. H. (1948). Proc. Mayo Clinic, 23, 129.

5b. - Clagett, O. T., Burchell, H. B., and Wood, E. H. (1948). Proc. Mayo Clinic, 23, 352.

6. Campbell, M., and Bayliss, J. H. (1956). Brit. Heart J., 18, 475.

7. Clagett, O. T., and Jampolis, R. W. (1951). Arch. Surg., 63, 337.

8. Cleland, W. P., Counihan, T. B., Goodwin, J. F., and Steiner, R. E. (1956). Brit. med. J., 2, 378.

9. Counihan, T. B. (1956). Clin. Sci., 15, 149.

10. Crafoord, C. (1948). Brit. Heart J., 10, 71 .

11. —, and Nylin, G. (1945). J. thor. Surg., 14, 347.

12. Culbertson, J. W., Kirkendall, W. M., Eckstein, J. W., and Bedell, G. N. (1954). J. clin. Invest., $33,926$.

13. Donald, K. W., Warmald, P. N., Bishop, J. M., and Taylor, S. H. (1958). Brit. Heart J., 20, 290, Proc.

14. Fanjoux, J., Oustrieres, G., Vernant, P., and Mathey, J. (1957). Arch. Mal. Coeur, 50, 833.

15. Ford, F. R. (1957). Bull. Johns Hopk. Hosp., 100, 14.

16. Friedman, M., Selzer, A., and Rosenblum, H. (1941). J. clin. Invest., $20,107$.

17. Fuller, J., Taylor, B. E., Clagett, O. T., and Wood, E. H. (1952). J. Lab. clin. Med., 39, 10.

18. Genest, J., Newman, E. V., Kattus, A. A., Sinclair-Smith, B., and Genecin, A. (1948). Bull. Johns Hopk. Hosp., $83,429$.

19. Gerbode, F., and Hultgren, H. (1951). Surg., 29, 441.

20. Glenn, F., and O'Sullivan, W. D. (1952). Ann. Surg., 136, 770.

21. Goldblatt, H., Kahn, J. R., and Hanzal, R. F. (1939). J. exp. Med., 69, 649.

22. Grollman, A., and Ferrigan, J. P. (1934). Arch. intern. Med., 53, 35.

23. Gross, R. E. (1945). Surg., 18, 673.

24. 1 (1953). Circ., 7, 757 .

25. Grow, J. B., Demong, C. V., and Rundles, W. R. (1956). Amer. Surg., 22, 1168.

26a. Gupta, T., and Wiggers, C. J. (1951). Circ., 3, 17.

26b. - (1951). Circ., 3, 32.

27. Hallenbeck, G. A., Wood, E. H., Burchell, H. B., and Clagett, O. T. (1951). Surg., Gyn., Obs., 92, 75.

28. Hamilton, M., Pickering, G. W., Roberts, J. A. F., and Sowry, G. S. C. (1954). Clin. Sci., 13, 11.

29. Harris, J. S., Sealy, W. C., and DeMaria, W. (1950). Amer. J. Med., 9, 734.

30. Hafkenschiel, J. H., Crumpton, C. W., and Moyer, J. H. (1949). Proc. Soc. Exp. Biol. Med., 71, 165.

31. Heymans, C., Delaunois, A. L., and Heuvel-Heymans, G. van den (1953). Circ. Res., 1, 3.

32. King, J. T. (1937). Ann. intern. Med., 10, 802.

33. Lepere, R. A. (1957). Guy's Hosp. Rep., 106, 128.

34. Lewis, T. (1933). Heart, 16, 205.

35. Marion, P. (1958). Lyon chir., 54, 242.

36. Master, A. M., Dublin, L. I., and Marks, H. H. (1950). J. Amer. med. Ass., 143, 1464.

37. Nadas, A. S. (1957). Pediatric Cardiology. W. B. Saunders, Phila., 1.16.

38. Page, I. H. (1940). Amer. Heart J., 19, 218.

39. Pannucio, P., Caini, B., and Brunori, M. (1956). Folia Cardiol., 15, 381.

40. Pickering, G. W. (1935-36). Clin. Sci., 2, 209.

41. - (1958). High Blood Pressure. Grune and Stratton, N. Y., p. 170.

42. Prinzmetal, M., and Wilson, C. (1936). J. clin. Invest., 15, 63.

43. Ring, D. M., and Lewis, F. J. (1956). J. thor. Surg., 31, 718.

44. Rytand, D. A. (1938). J. clin. Invest., 17, 391.

45. Scott, H. W., and Bahnson, H. T. (1951). Surg., 30, 206.

46. Sealy, W. C., DeMaria, W., and Harris, J. S. (1950). Surg., Gyn., Obs., 90, 193.

47. - Harris, J. S., Young, G. W., and Callaway, H. A. (1957). Surg., 42, 135.

48. Smeloff, C. H., Bauersfeld, S. R., and Kent, E. M. (1957). Ann. Surg., 146, 450.

49. Spencer, M. P., Johnston, F. R., and Meredith, J. H. (1958). Amer. Heart J., 56, 722.

50. Steele, J. M. (1941). J. clin. Invest., 20, 473.

51. Stewart, H. J., and Bailey, R. L. (1941). J. clin. Invest., 20, 145.

52. Surgical Advisory Committee, Amer. Coll. Chest Physicians (1957). Dis. Chest, 31, 468.

53. Tonelli, L., Baisi, F., and Malizia, E. (1954). Act. med. Scand., 148, 35.

54. Vadovskaya, Yu. D. (1956). Bjull. eksper. biol. med., 41, 23.

55. Vale, R. J. (1956). Guy's Hosp. Rep., 105, 232.

56. Wakim, K. G., Slaughter, O. L., and Clagett, O. T. (1948). Proc. Mayo Clin., 23, 347.

57. Werko, L., Bucht, H., and Karnell, J. (1956). Scand. J. Clin. Lab. Invest., 8, 193.

58. Woodbury, R. A., Murphy, E. E., and Hamilton, W. F. (1940). Arch. intern. Med., 65, 752.

59. Wright, J. L., Burchell, H. B., Wood F. H., Hines, E. A., and Clagett, O. T. (1956). Circ.,14, 806. 